\title{
Significados da morte de crianças com câncer: vivências de mães de crianças companheiras de tratamento
}

\author{
Significance of death of children with cancer: \\ Experiences of mothers of children \\ undergoing cancer treatment
}

\author{
Sheila Maria MAZER-GONÇALVES' \\ Elizabeth Ranier Martins do VALLE² \\ Manoel Antônio dos SANTOS ${ }^{2}$
}

\begin{abstract}
Resumo
O diagnóstico de câncer frequentemente suscita a consciência da possibilidade de morte. Admitir a morte na infância implica considerar que o ciclo vital se inverteu e que crianças também morrem. O objetivo deste estudo foi compreender os significados que mães de crianças que terminaram o tratamento oncológico atribuem à morte de outras crianças com câncer vivenciada no contexto hospitalar. Trata-se de uma pesquisa qualitativa com fundamentação fenomenológica. Foram realizadas entrevistas com sete mães cujos filhos haviam concluído tratamento em hospital terciário do interior paulista, audiogravadas e transcritas para análise compreensiva dos relatos. A compreensão do fenômeno estudado evidenciou que, quando as mães recordavam a morte de uma criança com câncer no hospital, significavam esse acontecimento com intensos sentimentos de frustração, tristeza e sofrimento. As participantes relataram de forma explícita que sentiam medo diante da morte de uma criança no hospital, pois isso as fazia pensar na possibilidade de morte do próprio filho ou da recidiva da doença.
\end{abstract}

Palavras-chave: Crianças; Fenomenologia; Hospitais; Mães; Morte; Neoplasias.

\begin{abstract}
Cancer diagnosis often leads to fear of death. Facing the death of children implies admitting the reversal of life cycle and that children also die. The aim of this study was to understand the significance attributed by mothers whose

$\nabla \nabla \nabla$

1 Universidade de São Paulo, Faculdade de Filosofia, Ciências e Letras de Ribeirão Preto, Departamento de Educação, Informação e Comunicação. Ribeirão Preto, SP, Brasil.

2 Universidade de São Paulo, Faculdade de Filosofia, Ciências e Letras de Ribeirão Preto, Programa de Pós-Graduação em Psicologia. Av. Bandeirantes, 3900, Monte Alegre, 14090-901, Ribeirão Preto, SP, Brasil. Correspondência para/Correspondence to: M.A. SANTOS. E-mail: <masantos@ffclrp.usp.br>.

Artigo elaborado a partir da dissertação de S.M. MAZER-GONÇALVES, intitulada "Impacto da morte de crianças com câncer no ambiente hospitalar: vivência das mães das crianças companheiras de tratamento". Universidade de São Paulo, 2007.

Apoio: Coordenação de Aperfeiçoamento de Pessoal de Nível Superior e Conselho Nacional de Desenvolvimento Científico e Tecnológico.
\end{abstract}


children have completed cancer treatment to the death of other children undergoing cancer treatment at the hospital. This is a qualitative phenomenological research. Individual in-depth interviews were conducted with seven mothers of children who had already completed oncologic treatment at a tertiary hospital in São Paulo State, Brazil. The interviews were audio recorded and transcribed for comprehensive analysis of recorded data. The understanding of the phenomenon studied shows that when the mothers recalled the death of a child with cancer at the hospital, the significance they attributed to that event was expressed with strong feelings of frustration, sorrow, and pain. The participants explicitly reported feeling fear whenever a child died at the hospital because it made them think about the possibility of their own child's death or relapse of the disease.

Keywords: Child; Phenomenology; Hospitals; Mothers; Death; Neoplasm.

A morte, em geral, é um assunto cercado por constrangimento e silêncio, o que expressa o desconhecimento e a dificuldade do ser humano em lidar com esse tema de modo natural, como um fato da vida (Borges et al., 2006; Santos \& Hormanez, 2013). Em especial, quando a finitude na infância é abordada, a morte é vista como uma calamidade. Esse contexto parece destoar do que o senso comum considera como uma realidade plausível, uma vez que é difícil compreender que o ciclo vital se inverteu, já que crianças também morrem (Costa \& Ceolim, 2010; Melo, 1999; Vendruscolo, 2005).

O diagnóstico de câncer traz consigo a consciência da possibilidade de morte e essa ideia vem comumente acompanhada por vivências de angústia e temores que perpassam o desenrolar do tratamento. A debilidade orgânica e a fragilidade psicológica, inerentes a uma doença grave como o câncer, costumam suscitar temores, preconceitos e estigmatização em uma sociedade na qual a terminalidade afronta a negação sistemática da morte, mostrando, pelo contrário, que todos os seres humanos são finitos e que esse desfecho é inevitável (Santos, Aoki, \& Oliveira-Cardoso, 2013).

No câncer infantil, frequentemente, os primeiros sinais e sintomas da doença aparecem diante de queixas inespecíficas, o que pode retardar o diagnóstico (Rodrigues \& Camargo, 2003; Silva, Hoffman, Andrade, Macedo, \& Barbosa, 2009; Vargas, 2000). O diagnóstico do câncer infantil é bastante complexo e difícil de ser realizado. As neoplasias malignas são descritas em termos de alterações no material genético das células. Ocorrem quando mutações nos genes de uma única célula a tornam capaz de proliferar-se rapidamente, a ponto de

614 formar uma massa tumoral. Sucessivas transfor- mações têm que ocorrer na mesma célula para que ela adquira o caráter de malignidade (Yamaguchi, 2002).

O tratamento oncológico envolve três modalidades principais: quimioterapia, cirurgia e radioterapia, e é realizado em um período que varia de seis meses a dois anos ou mais. Na criança, é preciso ter um cuidado especial pelo fato do paciente estar em idade de crescimento e desenvolvimento e, portanto, ter um organismo imaturo. O uso da radiação e de medicação quimioterápica pode acarretar inúmeros efeitos adversos e, inclusive, futuros problemas de saúde. Por conta disso, a criança deve permanecer em acompanhamento mesmo após o término do tratamento (Yamaguchi, 2002).

A avaliação do estado clínico da criança é realizada periodicamente, durante todo o tratamento, para verificar se houve evolução ou involução da doença. Os exames realizados para esse fim geralmente despertam muita apreensão, tanto para o paciente quanto para os cuidadores familiares - em geral, a mãe -, pois podem levá-los a experimentar ansiedade ou a criar esperanças na eficácia dos resultados (Yamaguchi, 2002). Com os avanços alcançados pela medicina, em termos de detecção, procedimentos cirúrgicos e farmacológicos, e o advento da radioterapia, houve um aumento significativo nas taxas de cura. O estigma de enfermidade fatal foi trocado por uma nomenclatura de doença crônica, mas, ainda assim, o câncer continua a carrear a ideia de morte e a ser vinculado, no imaginário social, ao sofrimento e à dor (Ambrósio \& Santos, 2011).

Entretanto, é preciso reconhecer que o tratamento oncológico melhorou muito nas últimas três décadas (Becker \& Pinda Chile, 2003). Na oncologia 
pediátrica, os dados apontam que sobreviventes de longa data aumentaram de 28\%, em 1960, a até $70 \%$, em 1990. Considera-se que tratamentos avançados contra o tumor, como a quimioterapia, novos procedimentos cirúrgicos, radiação, transplante de medula óssea, controladores da imunidade e novas combinações de quimioterápicos são fatores responsáveis pelo aumento do número de sobreviventes (Ellis, 2000). O incremento das taxas de sobrevivência e, por conseguinte, dos sobreviventes de longa duração, não se deve somente ao aprimoramento dos tratamentos, mas também à melhoria da detecção precoce, o que permite um tratamento mais rápido e eficaz (Rodrigues \& Camargo, 2003). Outro fator associado é o aumento da incidência de câncer que, a par da eficácia da detecção e dos tratamentos, leva a um número crescente de sobreviventes.

A despeito do câncer evidenciar, atualmente, maior possibilidade de cura e sobrevida dos pacientes, ainda ocorrem muitas mortes (Vendruscolo, 2001). No Brasil, o câncer já representa a segunda causa de mortalidade entre crianças e adolescentes de um a 19 anos (Costa \& Ceolim, 2010).

Embora a sociedade, de uma forma geral, repudie a morte, embates vêm sendo travados por parte das Ciências Humanas, inclusive a Psicologia, no sentido de vencer esse tabu. Já na década de 1970, Torres (2002) identificou um incremento nas publicações científicas sobre o tema. Este vem sendo cada vez mais estudado, mostrando os esforços para derrubar os estigmas da morte interdita característica do século XX e do início do século XXI (Kovács, 2008).

Para Hoffmann (1993), a morte, embora presente direta ou indiretamente na vida de qualquer ser humano, não é uma questão fácil de ser discutida. Há condicionamentos que operam no psiquismo das pessoas, impedindo-as de aceitá-la como parte irredutível de suas vidas. Quando o assunto é morte na infância, a dificuldade torna-se ainda maior, refletindo a ideia de uma vida que não se teria cumprido, uma vez que foi ceifada prematuramente. Nesse sentido, a morte de crianças geralmente gera comoção, incredulidade e perplexidade, além de ter forte repercussão social. É um evento impensável, inaceitável e constrangedor para a maioria das pessoas.

Segundo Chiattone (2001), a partir do século XIX, a morte de crianças tornou-se a menos tolerável de todas. Era considerada natural durante a era medieval, passando a ser ocultada, revestida pelo silêncio e banida do discurso cotidiano na modernidade. Essas atitudes são compatíveis com a maneira como a temática é tratada pela cultura ocidental. A morte de crianças é revestida de especial crucialidade, pois, no imaginário coletivo, a criança é sinônimo de alegria, vigor, energia, crescimento, futuro, e não de finitude e terminalidade (Melo \& Valle, 2004).

Embora cada profissional da equipe de saúde tenha tarefas específicas a desempenhar, todos se envolvem intensamente com os cuidados com a criança e a família, especialmente com a mãe, quando esta é a cuidadora principal (Chiattone, 2001; Santos et al., 2011; Valle, 2002). Por essa razão, a questão de pesquisa que motivou o presente estudo foi entender se a morte de uma criança com câncer no hospital é um evento crítico, que causa significativo impacto sobre as mães cuidadoras de outras crianças sob tratamento. Esse impacto também repercute no rompimento de vínculos - entre a criança que faleceu e os demais companheiros de tratamento, bem como entre as mães dessas crianças e entre as díades mãe-filho e equipe cuidadora (médicos, equipe de enfermagem, psicólogos, assistente social, nutricionista e voluntários que compõem o cenário do cuidado).

Assim, pode-se postular que todos os atores envolvidos no processo de terminalidade da criança sofrem diante da perda. Por isso, identificar e compreender os significados atribuídos ao evento pode fornecer à equipe de saúde subsídios e recursos relacionais para o aprimoramento da escuta das necessidades das famílias das crianças sobreviventes, contribuindo para humanizar a assistência. Com base no exposto, o objetivo deste estudo foi compreender os significados que mães, cujos filhos terminaram o tratamento do câncer infantil, atribuem à morte de outras crianças com câncer vivenciadas no contexto hospitalar. 


\section{Método}

Trata-se de um estudo de abordagem qualitativa, com fundamentação fenomenológica. Nesse tipo de pesquisa, a noção de fenômeno implica aquilo que se manifesta à consciência (Martins \& Bicudo, 2011). É possível ter acesso ao fenômeno interrogado por meio da fala da pessoa que vivencia a situação investigada, à medida que ela, com seu discurso, descreve a situação que vivencia ou vivenciou (Bruns \& Holanda, 2001). No presente estudo, o fenômeno situado é o significado que mães, cujos filhos terminaram o tratamento do câncer infantil, atribuem à morte de outras crianças vivenciadas enquanto cuidavam de seus filhos, então hospitalizados.

O método fenomenológico apresenta-se à Psicologia como um recurso útil para pesquisar a vivência do sujeito em determinadas situações (Valle, 1997), sendo que "vivência" é entendida como a percepção que o ser humano tem de suas próprias experiências, atribuindo-lhes significado (Forghieri, 1993). Assim, obter as falas dos participantes na pesquisa fenomenológica, por meio de entrevistas abertas, possibilita ter acesso às vivências dos sujeitos e aos significados a elas atribuídos.

\section{Participantes}

Foram entrevistadas sete mães, com idades entre 32 e 46 anos, cujos filhos haviam terminado o tratamento oncológico. Entre as crianças havia quatro meninas e três meninos, com idades entre três e 10 anos e diagnósticos de leucemia (quatro ocorrências), linfoma não-Hodgkin (uma) e tumores sólidos - hepatoblastoma e sarcoma (duas). O tempo de tratamento variou de um a três anos e um mês, e o tempo fora de tratamento (em remissão), de um a nove meses.

Os nomes próprios das mães e das crianças utilizados neste estudo são fictícios, de modo a preservar o anonimato e a confidencialidade dos dados. Foram atribuídos nomes de flores para as mães e de pedras preciosas para as crianças. Foram incluídas todas as mães cujos filhos haviam concluído o tratamento em até 12 meses na época de obtenção dos depoimentos (agosto a novembro de
2008) e que haviam presenciado a morte de pelo menos uma criança em tratamento oncológico. A escolha das mães como participantes se justifica pelo fato de serem as principais cuidadoras familiares no serviço de oncopediatria no qual se realizou esta investigação e, assim, terem tido a oportunidade de acompanhar de perto a terminalidade de outras crianças assistidas nesse contexto.

\section{Instrumentos}

Seguiu-se o procedimento da pesquisa de fundamentação fenomenológica proposto por Martins e Bicudo (2011). As entrevistas abertas foram iniciadas com a questão norteadora: "Possivelmente, você já vivenciou, aqui no hospital, situações em que uma criança é curada de câncer, mas também há situações em que o tratamento não é bem-sucedido e a criança acaba por morrer. Como é isso para você?".

\section{Procedimentos}

As entrevistas foram realizadas individualmente, em sala reservada junto ao ambulatório de oncologia infantil de um hospital terciário do interior do Estado de São Paulo. Foram audiogravadas mediante anuência das participantes e, posteriormente, transcritas na íntegra e de forma literal para análise compreensiva dos discursos maternos.

Martins e Bicudo (2011) sugerem que, a partir dos dados obtidos, a análise compreensiva seja realizada por meio da leitura geral do material, a fim de compreender, de forma intuitiva, o modo do sujeito existir na situação que descreve. Posteriormente, foram realizadas leituras atentivas do material descritivo, quantas vezes foram necessárias até que emergisse a compreensão da fala do sujeito relacionada ao objetivo da pesquisa, possibilitando a apreensão das unidades de significado. Cada unidade de significado foi transformada, por meio de um trabalho reflexivo dos pesquisadores, em discurso científico, o qual buscou realçar as convergências e divergências existentes entre as unidades de significado. 
A partir desse procedimento foi possível construir as categorias temáticas. Para Martins e Bicudo (2011), a repetição de temas indica que foi possível chegar ao significado ou essência do fenômeno estudado. Por fim, a pesquisadora articulou uma compreensão a partir das categorias temáticas, realizando uma descrição consistente da estrutura do fenômeno situado.

Este estudo foi aprovado pelo Comitê de Ética em Pesquisa da instituição hospitalar, sob o Parecer $n^{\circ} 11225 / 2005$. Foram seguidos todos os princípios éticos regulamentados pela Resolução n 196/96 (Brasil, 2011). As participantes assinaram o Termo de Consentimento Livre e Esclarecido.

\section{Resultados e Discussão}

A análise dos relatos maternos possibilitou articular as unidades de significado, que constituíram as categorias temáticas. Essas categorias evidenciam os significados atribuídos pelas mães à morte de crianças com câncer ocorridas concomitantemente ao tratamento oncológico de seus filhos. A análise fenomenológica dos discursos permitiu desvelar três categorias temáticas. Esses resultados serão apresentados e discutidos com o auxílio de fragmentos de falas ilustrativas das participantes, buscando-se alcançar a compreensão do significado do fenômeno em estudo.

\section{A morte durante o tratamento significa a perda da batalha contra o câncer}

Ao discorrerem sobre suas vivências durante o tratamento dos filhos, as mães entrevistadas evocaram lembranças de momentos de intenso sofrimento e que se acentuavam diante de algumas ocorrências: quando o cabelo da criança caía em decorrência do tratamento, quando era realizado algum procedimento doloroso, como a quimioterapia intratecal, por ocasião da internação e também quando presenciavam a perda de outras mães, cujos filhos vinham a óbito.

Frente à possibilidade de evocarem essas experiências penosas durante a entrevista, as mães desvelaram os significados que a morte tinha para elas na situação investigada. A metáfora da "batalha" emergiu durante as entrevistas para se referir ao tratamento oncológico. Esse foi também o sentido atribuído ao tratamento do câncer: uma batalha que deve ser vencida a qualquer custo, travada contra um inimigo poderoso, implacável e insidioso. E, como em todo evento desse tipo, existem vencedores e vencidos ao longo do percurso.

A grande batalha entre a vida e a morte instaura um tempo de incerteza. Diante da possibilidade de finitude do filho, os pais podem ser tomados por angústia avassaladora, sobretudo em momentos de maior vulnerabilidade e risco de vida (Arruda-Colli, Perina, \& Santos, 2015). Para as mães, perder um filho pode representar um fracasso em sua função protetora da vida de uma criatura frágil, ainda em processo de desenvolvimento. De fato, a criança é considerada um ser que ainda não desabrochou para a vida. Desse modo, as mães podem se sentir traídas pela vida, "abandonadas" pela criança e confrontadas com um vazio insuportável (Valle, 2002). O luto dos pais costuma tomar proporções de sofrimento muito intenso porque afeta as dimensões individual, familiar e social (Bolze \& Castoldi, 2005; Menezes, Passareli, Drude, Santos, \& Valle, 2007).

Quando as mães entrevistadas relembravam o que a morte de crianças que não resistiram ao avanço da doença ou às complicações decorrentes da terapêutica durante o período em que seus filhos estavam em tratamento, ou seja, as crianças que perderam a batalha, revelaram que presenciar esse acontecimento no hospital gerou frustração e sofrimento.

\begin{abstract}
Antes de fazer as últimas quimios da Ametista, eu lembro que ela estava fazendo e morreu a Da... não sei se você conhecia ela... morreu o D., o L. ... . Então, eu não achava que, quando os três faleceu, fosse tudo ao mesmo tempo. Um foi na sexta, outro no sábado, depois foi a Da. Aí foi muito sofrimento, não tem explicação (Azaléia, mãe de Ametista).
\end{abstract}

As mães também mostraram certa perplexidade e indignação perante a morte de crianças com 
quem conviveram durante uma parte do longo percurso de tratamento de seus filhos. Nesses momentos dolorosos, especulavam sobre a fatalidade dessas mortes inexplicáveis, examinavam os sentimentos despertados nas mães daquelas crianças que haviam perdido a batalha contra o câncer e se mostravam consternadas pela ausência.

Por que que morre? Por que que a gente perde, depois que luta tanto? Isso aí nem os médicos podem explicar pra gente... . Ficar assim, com uma criança, uma coisinha assim, já passa mal, já perde, já volta, né. Só Deus para saber mesmo (Tulipa, mãe de Topázio).

Quando o diagnóstico de câncer é definido, impõem-se, na dinâmica familiar, certas mudanças que inauguram outra temporalidade, diferente da que organizava a rotina anterior à doença. Para as mães, há o impacto de se ver diante de uma doença grave que ameaça a vida da criança e isso mobiliza ansiedade, temores e sentimento de impotência que impactam nas relações familiares. Receber o diagnóstico de uma doença grave na criança é um fator de desestruturação psicológica, pois essa situação faz a família se defrontar com a perda da ilusão de invulnerabilidade, desencadeando fortes sentimentos associados à angústia de morte (Ambrósio \& Santos, 2011; Chiattone, 2001; Santos et al., 2011). Uma das possibilidades é o recurso à fé e à religiosidade, na busca de respostas para o inexplicável: "Só Deus para saber mesmo", conforme o relato de Tulipa, diante dos insondáveis mistérios.

As participantes revelaram que se identificavam com as mães que perderam seus filhos, colocando-se empaticamente no lugar delas, adotando sua perspectiva e demonstrando compaixão. Tentavam imaginar a dor que sentiriam se, por acaso, fosse seu próprio filho a tombar durante a batalha.

Ah, eu fiquei com muita pena da mãe dele... . É porque é duro, né. Você fica aí a vida toda tentando conseguir uma coisa e depois você perder tudo. Eu fiquei com muita dó (Jasmim, mãe de Jade).
As mães lamentaram o fato de somente elas vencerem a batalha, por estarem com o filho fora de tratamento naquele momento, enquanto que as outras mães, ao lado das quais tanto lutaram, não tiveram a mesma sorte. Rosa, mãe de Rubi, deixa explícito esse sentimento de pesar quando diz: "Você está na mesma luta que as pessoas, você vence, e a pessoa também lutou, passou pelo mesmo que você passou, e não consegue... . É triste, né?".

É possível perceber que, por dividirem a dor de terem um filho com câncer, as mães das crianças que sobreviveram ao tratamento estabeleceram um forte vínculo por identificação, pois lutavam a mesma batalha e sofriam juntas os efeitos da longa jornada. Dessa forma, cada perda era sentida como um revés compartilhado, o que despertava o sentimento de compaixão de umas pelas outras. As mães relataram frustração por terem lutado junto com a mãe que acabou perdendo seu filho. Sentem que venceram a batalha e a companheira de tratamento não.

Eu mesmo fico frustrada, porque a gente torce pelos companheiros da gente para correr tudo bem, como ocorreu com a gente... . Toda perda que acontece, para mim, sei lá, é uma frustração e tanto (Camélia, mãe de (ristal).

\section{A morte do companheiro de tratamento evoca a possibilidade da morte do próprio filho}

A morte de uma criança companheira de tratamento evidenciava, para as mães entrevistadas, a possibilidade de morte do próprio filho. As participantes trouxeram esse significado com bastante pesar, pois vivenciaram essas situações sob o medo constante da perda. O medo apareceu de forma explícita, como um sentimento predominante que permeia todas as etapas do tratamento oncológico, do diagnóstico ao desfecho final. Esse desenlace pode se dar seja com a morte propriamente dita ou com a sobrevida após o câncer, que é marcada pela convivência com a possibilidade da recidiva. 
Eu sei que não tem explicação, o que eu sinto não dá para expressar direito, o que eu sinto... só sei que não é bom o que a gente sente, né, durante o tratamento... eu não sei... só sei que é muito medo, eu pelo menos tenho muito medo. Medo da perda. É uma doença assustadora, de que todo mundo tem medo. Você está numa situação dessa, só tem medo da perda (Camélia, mãe de (ristal).

As mães relataram, de forma explícita, que sentiam medo diante da morte de uma criança no hospital, pois esse fato trazia à baila a concretude da morte por câncer infantil. Afinal, era uma criança que fazia tratamento naquele mesmo hospital, com a mesma equipe de saúde e que convivia com seu filho no mesmo espaço físico. A outra mãe partilhava as mesmas dificuldades, atribulações e angústias. Nesse cenário, a morte presentifica o esgotamento de todos os recursos e esforços heroicos empreendidos pela equipe para preservar a vida da criança. Por isso, sua sombra se projeta sobre toda a família, abatendo o ânimo e aniquilando as últimas esperanças.

Por mais que, racionalmente, as mães saibam que a possibilidade de morte é um dado de realidade para aqueles que enfrentam a luta contra o câncer, confrontar a cessação da vida é uma vivência brutal e devastadora.

... . Mas, desde quando a gente sabe que aconteceu uma coisa dessa [a morte de uma criança em tratamento], é uma tristeza, meu Deus do céu, dá medo de acontecer com a gente (Camélia, mãe de Cristal).

As mães relataram, também, que tinham muitas fantasias quando a notícia da morte de uma criança era veiculada pelos corredores do hospital. Em suas reflexões, buscavam causas e explicações para esse acontecimento adverso e para os sentimentos que essa perda lhes despertava, o que corrobora a literatura especializada (Santos et al., 2011). Para Orquídea, a morte também é significada como rompimento do vínculo com a mãe da criança que faleceu.

Assim, eu fiquei sabendo de umas crianças que eu não conheci a mãe não, e de outras eu conhecia... . Mas só que aí, eu vinha no retorno, ficava sabendo, mas não encontrava as mães mais. Aí fica escutando as outras histórias e pensa que vai acontecer com a gente também (Orquídea, mãe de Ônix).

Na fala de Orquídea, nota-se o mal-estar vivenciado devido ao silêncio que envolve a morte das crianças que estiveram em tratamento. Esse velamento impede a elaboração psicológica dos não-ditos e interditos que cercam o desaparecimento dos pequenos. Essa mãe deduz o que aconteceu a partir das histórias fragmentadas ouvidas nos corredores do ambulatório. O pensamento de que a morte pode, um dia, colher também seu próprio filho se impõe como uma fantasia aterrorizante, a qual se torna ainda mais avassaladora na medida em que faltam espaços institucionalizados para ventilá-la.

Tulipa, mãe de Topázio, mostra em seu relato a ambiguidade que paira sobre o tratamento quimioterápico: se, por um lado, contém o câncer, por outro, pelo fato de ser invasivo e agressivo, debilita o organismo, provoca dor, sofrimento, mutilação, podendo até mesmo levar à morte em razão de sua alta toxicidade.

A única coisa mesmo é que a gente fica sabendo do que aconteceu pelos outros. Eu não posso afirmar porque eu nunca vi nada, porque é sempre depois das quimio... (Tulipa, mãe de Topázio).

O fato de não presenciar, mas apenas "ficar sabendo do que aconteceu" pela voz dos "outros" pode incrementar as fantasias apavorantes das mães das crianças sobreviventes. O que não se vê também não se controla, logo, pode se tornar ainda mais amedrontador. Desse modo, o medo suscitado pelo desconhecido acompanha os cuidadores, podendo ser reagudizado durante o tratamento nas situações em que a criança enfrenta uma intercorrência ou sofre algum revés, como quando morre um companheiro de tratamento.

Durante o começo do tratamento, quando fala que [o câncer] volta, o medo é um só, porque eu penso assim, se aconteceu com eles, pode acontecer com a gente (Camélia, mãe de Cristal). 
Esse excerto de fala mostra que, mesmo quando a criança logra concluir o tratamento, não há espaço para qualquer triunfalismo. A mãe sente que não pode "baixar a guarda" e respirar aliviada, porque sabe serem incertos os rumos da cura e que deve, portanto, conviver permanentemente com a incerteza gerada pela possibilidade da recidiva. Essa condição emocional, que se manifesta em pacientes oncológicos em remissão e em seus familiares, já está bem descrita na literatura do câncer infantil sob a denominação de Síndrome de Dâmocles (Koocher \& O'Malley, 1981). Esses achados são consistentes com a literatura especializada (Oliveira, Santos, \& Mastropietro, 2010) e corroboram a necessidade de apoio psicológico para que os familiares cuidadores possam expressar livremente seus sentimentos, ventilar suas emoções, compartilhar suas experiências, fantasias e temores vivenciados no cenário hospitalar.

\section{A possibilidade de recidiva da doença como presságio de morte}

O medo suscitado pela morte de outra criança em tratamento também aparece frente à ameaça de recidiva. O fato do filho estar sendo acompanhado no ambulatório, como parte das medidas preconizadas para o controle da doença, uma vez que se completou o tratamento oncológico, é considerado uma vitória contra o câncer. Uma batalha foi ganha, mas isso não significa que a guerra foi vencida. Pode-se dizer, apenas, que não perderam a guerra, pois as crianças, nesse estágio, ainda não foram consideradas tecnicamente "curadas" e têm pela frente uma jornada de cinco anos antes da notícia da diminuição da probabilidade de recorrência. A rigor, não se deve falar de cura do câncer, mas de período livre de doença. Quanto maior esse período, melhor é o prognóstico.

Aí a gente fica sabendo que tem pessoa que faz um ano de tratamento, aí [o câncer] volta... . Acha que está curado, mas volta. Aí você fica sem saber o que pensar... . Sem saber o que fazer (Tulipa, mãe de Topázio).

A constatação da imprevisibilidade que mar620 ca o tratamento oncológico (Chiattone, 2001; Me- nezes et al., 2007) é vivenciada com angústia e temor frente ao desconhecido. Como já referido anteriormente, o medo da morte permeia inexoravelmente todas as etapas do tratamento oncológico, do início ao final, qualquer que seja seu desfecho. A perda de um filho impacta os pais de forma inexorável (Morelli, Scorsolini-Comin, \& Santos, 2013), mas a antecipação dessa perda pode ser tão ou mais dolorosa do que a experiência real, desencadeando vivências de luto antecipatório. Durante o longo tempo de espera, as mães têm de conviver com a possibilidade da recorrência da doença, evidenciando a necessidade de viver uma nova jornada e reconhecendo que esse retorno, na maioria das vezes, exige um tratamento mais difícil e com menores possibilidades de vitória.

... . E a gente tá vendo que tá dando tudo certo... mas o medo da volta... ai, eu morro de medo da volta... . Eu não estaria preparada para mais uma jornada (Camélia, mãe de (ristal).

Como se pode depreender da fala de Camélia, as mães mencionam que passaram a ter medo do futuro. A possibilidade de recidiva é significada como vivenciar o árduo recomeço de uma jornada extenuante, é voltar à estaca zero. Isso potencializa fantasias ameaçadoras, suscitadas ou reativadas pela perda de companheiros de tratamento. Nesse contexto, a recidiva é significada como presságio de morte.

\section{Considerações Finais}

O presente estudo buscou compreender os significados atribuídos à morte de outras crianças com câncer, por mães cujos filhos haviam concluído o tratamento oncológico. A análise fenomenológica desvelou que essas mães, cujos filhos foram companheiros de tratamento de uma criança que morreu, são afetadas pela morte precoce de crianças que, assim como seus filhos, lutavam pela sobrevivência. Essas mães demonstraram certa indignação perante a morte desses pacientes com quem conviveram durante uma parte do tratamento oncológico, especulando sobre a fatalidade dessas perdas e os sentimentos experimentados pelas mães das 
crianças falecidas, imaginando a reação de pesar diante dessa ausência brutal. De certa forma, identificavam-se com elas, colocando-se empaticamente em seu lugar, imaginando a dor que sentiriam se seu próprio filho viesse a falecer.

O contato com o fenômeno da morte de crianças com câncer no ambiente hospitalar deixa marcas indeléveis nas mães dos companheiros de tratamento que conseguiram sobreviver. Isso se deve não apenas ao estigma que a doença carrega historicamente, ao ser vista como sinônimo de sofrimento e morte, mas também ao significado que a infância tem na sociedade. A morte da criança em si já é inconcebível, mas, quando associada a um câncer, impregna ainda mais de angústia e temores aqueles que mantêm um vínculo com o ser doente.

Por outro lado, esse fenômeno também adquire um significado de aproximar emocionalmente as mães, ao favorecer um laço de identificação que, se pudesse ser aproveitado e trabalhado na assistência, contribuiria para a transformação dos sentimentos negativos. Assim, dar acolhimento a essas mães parece ser imprescindível para corrigir a forte repercussão negativa do fenômeno investigado, reduzindo as inquietações que vivenciam durante o tratamento.

Este é, até onde se sabe, o primeiro estudo acerca da temática. A ausência de literatura impede a comparação dos resultados obtidos a partir de outros estudos sobre o impacto da morte de crianças com câncer nas mães cujos filhos completaram o tratamento oncológico. A despeito disso, acredita-se que os achados desta pesquisa podem contribuir para o avanço do conhecimento psicológico na área da Oncopediatria, favorecendo a compreensão das vivências dessas mães.

Uma das implicações dos resultados é chamar a atenção para a necessidade de tomar medidas para acolher os cuidadores, sempre que houver situações de morte de outras crianças em tratamento. Romper o silêncio que tende a se instalar após esses eventos adversos é uma medida necessária para cuidar da saúde mental das mães das crianças sobreviventes e mesmo daquelas que vivenciaram a dura experiência de ter um filho morto. Uma das possibilidades seria desenvolver estudos acerca da eficácia de um protocolo de "intervenção" com os cuidadores que passam por essa situação, com vistas a atenuar o impacto emocional dessa vivência potencialmente traumatogênica.

Os dados obtidos auxiliam os profissionais envolvidos com a assistência às mães e aos demais familiares de crianças com câncer a se tornarem mais sensíveis às suas necessidades. Os resultados mostram que é preciso criar dispositivos de escuta para que as mães possam conversar livremente sobre fatos perturbadores que atravessam o longo percurso do tratamento de seus filhos, como é o caso da perda de crianças que, caso continuem sem elaboração, podem se tornar ainda mais catastróficos.

Parece ser imprescindível disponibilizar uma escuta para os significados atribuídos à morte de outras crianças com câncer por mães das sobreviventes ao tratamento oncológico. Falar sobre morte apenas em situação de terminalidade não é suficiente. É preciso ampliar os contextos dialógicos nos quais a morte possa se tornar um assunto conversável em diferentes estágios do tratamento. Desse modo, seria possível examinar com cautela como as famílias, a equipe de saúde e as próprias crianças lidam com essa possibilidade que advém de uma doença tão grave como o câncer, ampliando, assim, as possibilidades de emergirem outros sentidos valorativos para esse tema tão controvertido quanto negligenciado no contexto clínico e na pesquisa.

\section{Colaboradores}

Todos os autores contribuíram na concepção e desenho do estudo, análise de dados e redação final do artigo.

\section{Referências}

Ambrósio, D. C. M., \& Santos, M. A. (2011). Vivências de familiares de mulheres com câncer de mama: uma compreensão fenomenológica. Psicologia: Teoria e Pesquisa, 27(4), 475-484.

Arruda-Colli, M. N. F., Perina, E. M., \& Santos, M. A. (2015). Experiences of Brazilian children and family caregivers facing the recurrence of cancer. European 
Journal of Oncology Nursing, 19(5), 458-464. http:// dx.doi.org/10.1016/j.ejon.2015.02.004.

Becker, K. A., \& Pinda Chile. (2003). Pronóstico de vida y secuelas del tratamiento del cáncer en los niños. Revista Chilena de Pediatria, 74(5), 520-523.

Bolze, S. D. A., \& Castoldi, L. (2005). O acompanhamento familiar antes e depois da morte de criança: uma proposta de intervenção para o psicólogo hospitalar. Alethéia, 21, 79-91.

Borges, A. D. V. S., Silva, E. F., Toniollo, P. B., Mazer, S. M., Valle, E. R. M., \& Santos, M. A. (2006). Percepção da morte pelo paciente oncológico ao longo do desenvolvimento. Psicologia em Estudo (Maringá), 11(2), 361-369.

Brasil. Ministério da Saúde. (2011). Resolução nº 196, de 10 de outubro de 1996. Aprova as diretrizes e normas regulamentadoras de pesquisas envolvendo seres humanos. Diário Oficial da União, vol. 134, n² 201, out. 1996, Seção 1, p.21082.

Bruns, M. A. T., \& Holanda, A. F. (2001). Psicologia e pesquisa fenomenológica: reflexões e perspectivas. São Paulo: Omega.

Chiattone, H. B. C. (2001). A criança e a morte. In V. A. Angerami (Org.), E a Psicologia entrou no hospital (2a ed., pp.69-146). São Paulo: Cengage Learning.

Costa, T. F., \& Ceolim, M. F. (2010). A enfermagem nos cuidados paliativos à criança e adolescente com câncer: revisão integrativa da literatura. Revista Gaúcha de Enfermagem, 31(4), 776-784.

Ellis, J. A. (2000). Psychosocial adjustment to cancer treatment and other chronic illnesses. Acta Paediatrica, 89(2), 134-141.

Forghieri, Y. C. (1993). Psicologia fenomenológica: fundamento, método e pesquisas. São Paulo: Pioneira.

Hoffmann, L. (1993). A morte na infância e sua representação para o médico: reflexões sobre a prática pediátrica em diferentes contextos. Cadernos de Saúde Pública, 9(3), 364-374.

Koocher, G. P., \& O'Malley, J. J. (1981). The Damocles syndrome: Psychosocial consequences of surviving childhood cancer. New York: McGraw-Hill.

Kovács, M. J. (2008). Morte e existência humana: caminhos de cuidados e possibilidades de intervenção. São Paulo: Guanabara Koogan.

Martins, J., \& Bicudo, M. A. V. (2011). A pesquisa qualitativa em Psicologia: fundamentos e recursos básicos ( $5^{a}$ ed.). São Paulo: Centauro. (Originalmente publicado em 1989).

Melo, L. L. (1999). "E a luz está se apagando..." : vivências de uma criança com câncer em fase terminal. Revista Brasileira de Enfermagem, 2(4), 566-575.

Melo, L. L., \& Valle, E. R. M. (2004). A criança com câncer em iminência de morte: revisão de literatura. Acta Oncológica Brasileira, 24(3), 671-675.
Menezes, C. N. B., Passareli, P. M., Drude, F. S., Santos, M. A., \& Valle, E. R. M. (2007). Câncer infantil: organização familiar e doença. Revista Mal-Estar \& Subjetividade, 7(1), 191-210.

Morelli, A. B., Scorsolini-Comin, F., \& Santos, M. A. (2013). Impacto da morte do filho sobre a conjugalidade dos pais. Ciência \& Saúde Coletiva, 18(9), 2711-2720.

Oliveira, E. A., Santos, M. A., \& Mastropietro, A. P. (2010). Apoio psicológico na terminalidade: ensinamentos para a vida. Psicologia em Estudo (Maringá), 15(2), 235-244.

Rodrigues, K. E., \& Camargo, B. (2003). Diagnóstico precoce do câncer infantil: responsabilidade de todos. Revista da Associação de Medicina Brasileira, 49(1), 29-34.

Santos, L. F., Marinho, K. C., Oliveira, R. R., Siqueira, K. M., Oliveira, L. M. A. C., Peixoto, M. K. A. V., \& Salge, A. K. M. (2011). Ser mãe de crianças com câncer: uma investigação fenomenológica. Revista Enfermagem UERJ, 19(4), 626-631.

Santos, M. A., \& Hormanez, M. (2013). Atitude frente à morte em profissionais e estudantes de enfermagem: revisão da produção científica da última década. Ciência \& Saúde Coletiva, 18(9), 2757-2768.

Santos, M. A., Aoki, F. C. O. S., \& Oliveira-Cardoso, E. A. (2013). Significado da morte para médicos frente à situação de terminalidade de pacientes submetidos ao transplante de medula óssea. Ciência \& Saúde Coletiva, 18(9), 2625-2634.

Silva, F. A. C., Hoffman, M. V., Andrade, P. R., Macedo, C. R., \& Barbosa, T. R. (2009). Representação do processo de adoecimento de crianças e adolescentes oncológicos junto aos familiares. Escola Anna Nery, 13(2), 334-341.

Torres, W. C. (2002). A criança diante da morte: desafios (2a ed.). São Paulo: Casa do Psicólogo.

Valle, E. R. M. (1997). Câncer infantil: compreender e agir. Campinas: Psy.

Valle, E. R. M. (2002). Vivências da família da criança com câncer. In M. M. M. J. Carvalho (Org.), Introdução à psiconcologia (pp.219-242). Campinas: Livro Pleno.

Vargas, L. (2000). Cáncer en pediatría: Aspectos generales. Revista Chilena de Pediatria, 71(4), 283-295.

Vendruscolo, J. (2001). A criança curada de câncer: modos de existir. In E. R. M. Valle (Org.), Psico-oncologia pediátrica (pp.247-292). São Paulo: Casa do Psicólogo.

Vendruscolo, J. (2005). Visão da criança sobre a morte. Medicina (Ribeirão Preto), 38(1), 26-33.

Yamaguchi, N. H. (2002). O câncer na visão da oncologia. In M. M. M. J. Carvalho (Org.), Introdução à psiconcologia (pp.21-34). Campinas: Livro Pleno.

Recebido: fevereiro 3, 2014

Versão final: maio 28, 2014

Aprovado: junho 18, 2014 